This is the author's final, peer-reviewed manuscript as accepted for publication. The publisher-formatted version may be available through the publisher's web site or your institution's library.

\title{
Physical activity and healthy eating in the after-school environment
}

Karen J. Coleman, Karly S. Geller, Richard R. Rosenkranz, David A. Dzewaltowski

\section{How to cite this manuscript}

If you make reference to this version of the manuscript, use the following information:

Coleman, K.J., Geller, K.S., Rosenkranz, R.R., \& Dzewaltowski, D.A. (2008). Physical activity and healthy eating in the after-school environment. Retrieved from http://krex.ksu.edu

\section{Published Version Information}

Citation: Coleman, K.J., Geller, K.S., Rosenkranz, R.R., \& Dzewaltowski, D.A. (2008). Physical activity and healthy eating in the after-school environment. Journal of School Health, 78(12), 633-640.

Copyright: (C 2008, American School Health Association

Digital Object Identifier (DOI): doi: 10.1111/j.1746-1561.2008.00359.x

Publisher's Link: http://onlinelibrary.wiley.com/doi/10.1111/j.1746-1561.2008.00359.x

This item was retrieved from the K-State Research Exchange (K-REx), the institutional repository of Kansas State University. K-REx is available at http://krex.ksu.edu 
Physical Activity and Healthy Eating in the After School Environment

Suggested citation: Coleman, K.J., Geller, K.S., Rosenkranz, R.R., \& Dzewaltowski, D. A. (2008). Physical Activity and Healthy Eating in the After School Environment. Journal of School Health. 78(12):633-640.

Karen J. Coleman ${ }^{1}$, Karly. S. Geller ${ }^{2}$, Richard R. Rosenkranz ${ }^{2}$, \& David A. Dzewaltowski ${ }^{3}$ The definitive version is available at www.blackwell-synergy.com or http://onlinelibrary.wiley.com/doi/10.1111/j.1746-1561.2008.00359.x/full

${ }^{1}$ Research and Evaluation, Southern California Permanente Medical Group, 100 S. Los Robles Ave., $2^{\text {nd }}$ Floor, Pasadena, CA 91101, Karen.J.Coleman@kp.org, phone (626) 564-3580, fax (626) 564-3409, ${ }^{2}$ Department of Human Nutrition and Community Health Institute, Kansas State University, Community Health Institute, Natatorium 8, Manhattan, KS 66506, geller@ksu.edu, richardo@ksu.edu, phone (785) 532-7750, ${ }^{3}$ Department of Kinesiology and Community Health Institute, Kansas State University, Community Health Institute, Natatorium 8, Manhattan, KS 66506, dadx@ksu.edu, phone (785) 5327750.

Correspondence: Karen J. Coleman, Ph.D., Research and Evaluation, Southern California Permanente Medical Group, 100 S. Los Robles Ave., $2^{\text {nd }}$ Floor, Pasadena, CA 91101; phone: (626) 564-3580; fax: (626) 564-3409; email: Karen.J.Coleman@kp.org. 


\begin{abstract}
Background: No research to date has extensively described MVPA and HE opportunities in the after-school environment. The current study described the quality of the after-school environment for its impact on children's MVPA and HE.

Methods: An alliance of seven elementary schools and boys and girls clubs who worked with the Cooperative Extension Service in Lawrence, KS was selected to participate in a larger intervention study. After school settings were observed for information regarding session type, session context, leader behavior, physical activity and snack quality using validated instruments such as SOFIT. Data presented are baseline measures for all sites.
\end{abstract}

Results: Participating children $(n=144)$ were primarily non-Hispanic white $(60 \%)$ and in fourth grade (69\%). After-school sites offered four different sessions per day (active recreation, academic time, non-active recreation, and enrichment activities. Children were provided with a daily snack. On 36\% of the days observed, this snack included fruit, fruit juice, or vegetables. There was significantly more time spent in MVPA during free play sessions (69\%) compared to organized adult-led sessions (51\%). There was also significantly more discouragement of physical activity during organized adult-led sessions (29\%) as compared to the free play sessions (6\%).

Conclusions: The quality of after-school programs can be improved by providing fruits and vegetables as snacks, offering more free play activities, training the after-school staff in simple, structured games for use in a variety of indoor and outdoor settings, and training after-school staff to promote and model MVPA and HE in and out of the after-school setting. 


\section{Introduction}

The dramatic increase in the prevalence of overweight among children and adolescents has led to obesity prevention becoming a major national health priority ${ }^{1-5}$. There is now an emerging body of evidence that at least four behaviors play a role in positive energy balance and the development of childhood obesity: lack of physical activity, lack of fruit and vegetable consumption, sugar-sweetened beverage consumption, and use of television and video games (screen time) $)^{6-14}$. It is estimated that in the US over $60 \%$ of children aged 9-13 years do not participate in any organized physical activity during their non-school hours and $23 \%$ do not engage in any free-time physical activity ${ }^{1}$. The data are equally discouraging for healthful eating (HE), with only $20 \%$ of children meeting the daily recommended five servings of fruits and vegetables ${ }^{1}$.

Settings, such as schools and after-school programs are ideal for reaching children and adolescents in order to promote HE and physical activity ${ }^{11,15}$. A number of school-based interventions aimed at promoting HE and/or physical activity behaviors have been implemented in the last 15 years ${ }^{11}$, with most having positive influences on moderate and vigorous physical activity (MVPA) and HE, and three studies having positive impacts on child obesity $\left(\mathrm{MSPAN}^{16}\right.$, Planet Health ${ }^{17-18}$, El Paso CATCH ${ }^{19}$ ).

School-based obesity prevention programs, however, face challenges due to a lack of physical education offered in public schools and a focus in the US on basic educational skills and test scores. Due to the gap in time that exists between parents’ working hours and their children’s school hours, programs offered after-school have been identified as one of the potentially important environments for child and adolescent health promotion efforts and may be a particularly effective place for obesity prevention $^{20}$.

A few investigations have examined the role of after-school programs in preventing obesity and/or promoting healthy behaviors ${ }^{21-28}$. A basic premise of all of these programs is that the after-school setting can provide physical activity and a healthy snack for children who do not engage in these 
behaviors. Furthermore, after-school programs can also place children in an environment where the opportunities for sugar sweetened beverage consumption and screen time are limited compared to being home alone. Despite the stated potential for after-school settings in the promotion of MVPA and HE, no study to date has systematically observed the after-school environment to determine the extent to which it does or does not promote MVPA and HE without outside intervention. The current study was designed to evaluate the opportunities offered in after-school for MVPA and HE in the Healthy Opportunities for Physical Activity and Nutrition (HOP’N) after-school project (www.hopnafterschool.org). Behavioral observation methods were used to collect data regarding a variety of child, instructor, and environmental variables important for promoting HE and MVPA. The primary aim of the HOP' $\mathrm{N}$ after-school project is to improve the quality of after-school programs to prevent obesity in children.

\section{Methods}

\section{Settings}

A community alliance of a local school district, Boys and Girls Club, Cooperative Extension Service, and other community partners in Lawrence, KS was approached to participate in the larger parent study. The alliance contained seven program sites and all sites agreed to participate. The community alliance was selected for the larger study for a variety of reasons: 1) it was the only one of its kind with multiple community partners; 2) it contained after school sites within 1.5 hours or less from the Kansas State University research team; and 3) all sites were part of the USDA Food Stamp Nutrition Education Program. The larger parent study was designed as a test of improved physical activity and nutrition education in the after school setting for this USDA program.....

\section{Participants}

A total of 144 third $(n=26)$, fourth ( $n=99)$, fifth $(n=16$, and sixth grade $(n=3)$ children had consent from their parents to collect demographic information and to have the research team measure height and weight. Of these students, 55\% were boys, $60 \%$ were non-Hispanic white, $21.5 \%$ African 
American, 10\% Native American, 5\% Hispanic, and 1\% Asian, 50\% were eligible for free/reduced lunch and thus classified as low income, and 37\% were either overweight (greater than 85 percentile according to CDC growth charts) or obese (greater than 95 percentile). All study methods were approved by the Institutional Review Board for Human Subjects Research at Kansas State University.

\section{Measures}

After-School Session Observation System. After-school settings were observed using an observation system developed by the authors to determine if the activities offered to children were academic, enrichment, recreational (active and non-active), or snack. Activities in these after-school settings were coded as academic if they were led or supervised by school, after-school, or partner organization personnel as an extension of the school day. These activities were typically homework or adult led sessions related to school day academic lessons. Enrichment was defined as an after-school session led or supervised by school, after-school, or partner organization personnel where the primary activity was not an extension of the school day. Enrichment was designed to build skills and improve a particular knowledge base ${ }^{29}$. Typical enrichment sessions included activities such as drug and alcohol prevention programs or drama club.

Recreational activities were classified as active or non-active. Active recreational involved any kind of physical activity, either organized by adult leaders or free play. Organized physical activities involved close supervision of an adult and had procedural aspects to them like adult-defined rules/boundaries/expectations. Free play was remotely supervised by an adult and did not involve adultdefined rules/boundaries/expectations. Non-active recreation did not involve physical activity, and was supervised or led by school, after-school, or partner organization personnel but did were not intended to build skills. Typical non-active recreational activities were board games and reading for fun.

Each after-school session was evaluated for the potential for physical activity using the environmental support categories from the System for Observing Play and Leisure Activity in Youth (SOPLAY) $)^{30-31}$. The SOPLAY categories describe the characteristics of the after-school environment for 
physical activity. Sessions were coded for environments that were usable for physical activity, supervised by after-school personnel, organized by adult leadership (after-school personnel or community partner), and the availability of equipment.

Active Recreation Sessions. All active recreation sessions were also observed using the System for Observing Fitness Instruction Time (SOFIT) ${ }^{32}$. SOFIT is an observational tool that records behavior every 20 seconds during a defined session and measures children’s physical activity level, session context, and leader behavior. Student physical activity levels were categorized on a 5-point scale: (1) lying, (2) sitting, (3) standing, (4) moderate, and (5) vigorous. The student activity level codes have been calibrated using heart rate monitors ${ }^{32-33}$ and validated using accelerometers ${ }^{34}$. Session context was specified according to the following categories: student management, physical activity- or nutritionspecific knowledge, fitness, skill drills, game play, or free play. The teacher behavior section of SOFIT was modified to specifically code after-school leader interactions with the children regarding physical activity and HE. Leader behavior was coded for verbal or non-verbal behaviors that promoted or discouraged student physical activity or HE behaviors. A code was also added for whether leaders encouraged or discouraged these child behaviors within the after-school setting or outside the afterschool setting (i.e. at home).

Snack Sessions. Observers also used SOFIT to measure leader behavior during snack sessions. Although snack offerings varied across sites, children were most often offered a choice between beverages and then simply given the snack food to eat. If a child wanted a second snack they were allowed to have one, although seconds were not offered to all children as a regular practice. The snack was only offered once per after school session. All of the snacks and beverages available to the children were documented and later analyzed. When needed, snack packages were collected for later analysis. Nutritional content of the snack was recorded using actual snack labels (if available), company website information for the snack, and/or the USDA calorie count website. If a snack did not have a label, a sample was weighed and information was obtained from the USDA calorie count website by weight. 
Total calories, fat calories, and grams of carbohydrate in a serving were recorded for all snacks. Percent fat was derived by dividing fat calories by total calories. Data are presented for an entire snack offered to children even if it was more than one serving.

\section{Observer Training and Reliability Assessment}

Nine observers were trained to perform the responsibilities of two different types of observers (A or B). Observer A recorded environmental characteristics, observations for type of instruction, leader behavior, and snack information while Observer B recorded the physical activity level of the children and session context during the active recreation sessions. Training and inter-observer reliability assessment consisted of one lab session and two field trials. The lab session involved the use of videotaped situations for discussion and memorization of data collection procedures and protocols. Once the lab session was completed, the first field trial was done. During the sessions in the first field trial, the second author and all observers coded three after-school sessions using SOFIT while discussing the codes they were using. After this trial run, the second author and observers would discuss any discrepancies in coding. A second field trial was used for collecting reliability data. The second author and each observer coded an after-school session on four separate days. Reliability was determined by calculating inter-observer percent agreement (IOA). The IOA was calculated for all behavioral categories by using the formula: [(Total \# Agree/Total \# Observed) x 100]. All observers using SOFIT had percent agreements $\geq 80 \%$ for child physical activity intensity, $\geq 97 \%$ on lesson context, and $\geq 94 \%$ on leader behavior.

\section{Procedures}

All after-school programs were observed on six days (three observations in fall semester and three observations in the spring semester) by at least two trained research assistants. Observation visits occurred no more than once a month at each site, and each observation was on a different day of the week: Monday, Tuesday and Thursday. Wednesdays were not chosen as observation days because the after school program was much longer due an early release schedule on this day and Fridays were not 
chosen for observation because attendance was lower than other days of the week. Visits were scheduled with the program manager in order to avoid holidays, field trips, and other special events. Program staff were not informed by the research team of the visit or the purpose of the observation. Once days with events were eliminated from the observation schedule, days were randomly scheduled to insure that a Monday, Tuesday, and Thursday were observed each semester of the school year. Snack observations were done at the same time as the activity observations.

\section{Data Analysis}

Data are presented as descriptive statistics with means \pm standard deviations for continuous variables and proportions for categories of behavior. The MVPA was calculated by summing the observed instances of students in moderate and vigorous physical activity. Differences between proportions were analyzed using the Chi Squared statistic for nonparametric data.

\section{Results}

\section{After-school Program Sessions}

Table 1 presents summary data for the types of sessions offered at the after-school programs. On average, after-school settings had four sessions per day. Every after-school day had a snack offered to children. Most sessions occurred less frequently than once per day, however, there was an average of 1.5 active recreation sessions per day. Across the six observation days, enrichment sessions were the longest when offered at 40.5 minutes, but occurred very infrequently such that the mean offerings per day was only 9.6 minutes. Active recreation sessions occurred the most frequently with a mean of 46.8 minutes offered per day and a mean length of 30.7 minutes for each instance they were offered. Students were spending an average of 15.1 minutes for snack time and 27.6 minutes in academics daily. With respect to the physical activity environments of the seven after-school settings, $98 \%$ were usable, 100\% were supervised, 85.5\% were equipped, and 55\% were organized. In addition, 53\% of observed recreational sessions occurred inside the school building (i.e. gymnasium, hallway) while $47 \%$ of all recreational sessions occurred outside of the school building on the playground. 


\section{Active Recreation Session Physical Activity by Session Context}

A variety of activities were recorded for active recreation sessions including basketball, dodgeball, regular and flag football, jump rope, gymnastics, running, soccer, tag, kickball, cleaning, cheerleading, and several follow-the-leader games. Table 2 summarizes the intensity of physical activity performed during active recreation sessions that were either organized or free play. Children performed more MVPA $\left(\mathrm{X}^{2}(1)=97.20 ; \mathrm{p}<.001\right)$ and VPA $\left(\mathrm{X}^{2}(1)=62.40 ; \mathrm{p}<.001\right)$ during the free play active recreation sessions (69\% and $25.5 \%$ respectively) as compared to the more organized sessions (51\% and $17 \%$ respectively).

Table 3 illustrates that the majority of time during organized active recreation was spent in game play $48 \%$, while in free play active recreation sessions, children participated mostly in free play (87\%). During the structured active recreation sessions there was much more management time (14.5\%) compared to the free play sessions (7\%). Furthermore, during management time in both organized (47\% of time) and free play (41\% of time) children were often standing.

\section{Leader Behavior}

Table 4 and Table 5 present leader behavior during organized active recreation or free play active recreation by physical activity intensity and session context, respectively. Results were not presented for HE because no instances of any kind of encouragement or discouragement of HE were recorded.

As Tables 4 and 5 illustrate, there were no instances observed where a leader encouraged their children to be physically active outside of the after-school setting. In general, there was significantly more encouragement for physical activity $\left(\mathrm{X}^{2}(1)=486.89\right.$; $\left.\mathrm{p}<.001\right)$ during organized active recreation (92\%) as compared to free play active recreation (41\%). When leaders discouraged physical activity, regardless of active recreation type, it was most likely to occur during management episodes (25\% for organized; 94\% for free play) or when “teaching” the children about how to do an activity (67\% for organized). In addition, leaders discouraged physical activity most often when children were standing 
(46\% for organized; $75 \%$ free play). There was significantly more encouragement than discouragement for physical activity during both organized (55\% vs. 29\%; $\left.\mathrm{X}^{2}(1)=65.62 ; \mathrm{p}<.001\right)$ and free play active recreation $\left(64 \%\right.$ vs. $\left.6 \% ; X^{2}(1)=36.00 ; \mathrm{p}<.001\right)$. There was significantly more discouragement $\left(\mathrm{X}^{2}(1)\right.$ $=36.00 ; \mathrm{p}<.001)$ of physical activity during organized active recreation $(29 \%)$ as compared to free play active recreation (6\%).

\section{Snack Content}

Sixty-three different drinks and foods were served to children in the after-school setting throughout the year on the six observation days. Drinks had an average of $119 \pm 12$ total calories, $19 \%$ from fat, and $17 \pm 1.6$ grams of carbohydrates. Drinks were either milk products (skim, $1 \%$ fat, $2 \%$ fat; strawberry, chocolate, plain) or 100\% fruit juice (grape, orange, apple). At no time was bottled water served to the children. Foods had an average of $186 \pm 53$ total calories, $28 \%$ from fat, and $27 \pm 2.8$ grams of carbohydrates. A variety of foods were offered including fruits (apples, bananas), vegetables (baby carrots with ranch and ranch lite dressing), breads (cinnamon roll, super donut, soft pretzel), cookies, snack bars, cereals, cheese, jams/jellies, and crackers. Fruits, fruit juice, and vegetables were the least frequently offered foods with an average of .36 servings/day offered to the children. Most of the offerings came in the form of fruit juice (.28 servings/day). Fruit and vegetables were offered infrequently (.08 servings/day).

\section{Discussion}

This study is the first to systematically describe MVPA and HE during the after-school environment, independent of outside intervention. Findings from these seven after school sites indicated that children were spending approximately 47 minutes of after-school time in active recreation, with $49 \%$ of this time in organized activities and 51\% in free play. Although other studies have reported that MVPA is lower during free play than during structured activity when children are in school ${ }^{35-36}$, we found that children in an after-school setting were spending significantly more time in MVPA while in free play than when in organized activities. This finding using SOFIT is consistent with our objectively 
monitored physical activity data ${ }^{37}$. The level of MVPA in both the organized and free play components of the active recreation time were comparable to or exceeded other estimates for in-school physical activity programs ${ }^{19,38,35-36}$, while the vigorous physical activity (VPA) findings exceeded many of those reported $^{38,35-36}$. This demonstrates that independent of any intervention, some after-school settings can be structured in such a way as to provide excellent opportunities for MVPA and VPA.

Our findings are also the first to look at specific leader behaviors with respect to encouraging or discouraging physical activity and HE in and out of the after-school setting. We found that as long as the children were moving, discouraging comments were kept to a minimum. However, leaders did discourage physical activity during organized sessions more so than during free play. This may reflect the lack of training that many after-school leaders have in conducting structured activities such as games $^{21}$. Programs such as the CATCH Kids Club are specifically designed to help leaders with minimal training conduct productive and positive structured activity with minimal management and discipline problems $^{21}$.

Although there was a snack at every observed after-school session, they were often high in carbohydrates such as sugar and high fructose corn syrup. The least common snack was a fruit or vegetable and the most common was some kind of bread or candy product. Although low fat milk and $100 \%$ fruit juice were the beverages offered (no soda), bottled water was never offered to the children. At no time did we observe after-school leaders encouraging healthy eating within or outside of the school setting. This is clearly a place where public health interventions could introduce basic, healthy nutrition information with a variety of healthier snacks for the children.

Findings from this study should be viewed as preliminary. Only seven after-school programs were observed, all within the city of Lawrence, KS. It is likely that these schools do not represent schools in other parts of the nation. In addition, schools were not chosen systematically for the study of after-school environments and their impact on children's health behaviors. These schools were chosen to be part of an after-school intervention program following baseline assessment of variables specific to the 
intervention outcomes (i.e. leader behavior encouraging PA and healthy eating). Given that so little is known about after-school environments, our findings suggest that a large, nation-wide, study of afterschool environments and children's health behaviors would contribute substantially to the planning and implementation of after-school programs with the maximum reach and impact on PA and healthy eating. Despite these limitations, this study provides clear, preliminary support for specific areas of intervention to promote MVPA and HE for children in these after-school settings in Lawrence, KS. These include providing access to water, fruits, and vegetables as snacks; training the after-school staff in simple healthy eating and physical activity messages as well as how to be more encouraging towards healthy choices within the after-school setting and at home; encouraging free play activities; training the after-school staff in simple, structured games for use in a variety of indoor and outdoor settings. These clear, simple modifications could make a substantial impact on the after-school setting in using it to promote healthy lifetime behaviors in young children. 


\section{Acknowledgements}

This study was supported by National Research Initiative Grant no. 2005-35215-15418 from the USDA Cooperative State Research, Education, and Extension Service Human Nutrition and Obesity Program. 


\section{References}

1. Eaton D, Kann L, Kinchen S, Ross J, Hawkins J, Harris WA, Lowry R, McManus T, Chyen D, Shanklin S, Lim C, Grunbaum JA, Wechsler H. Centers for Disease Control and Prevention. Youth Risk and Behavior Surveillance---United States, 2005. MMWR. 2006;55(SS05):1-108.

2. Centers for Disease Control and Prevention. Update: prevalence of overweight among children, adolescents, and adults-United States, 1988-1994. MMWR 1997;46(09):199-202.

3. Mokdad AH, Bowman BA, Ford ES, Vinicor F, Marks JS, Koplan JP. The continuing epidemics of obesity and diabetes in the United States. JAMA 2001;286(10):1195-1200.

4. Troiano RP, Flegal KM. Overweight children and adolescents: description, epidemiology, and demographics. Pediatrics 1998;101(3 Pt 2):497-504.

5. Summerbell CD, Waters E, Edmunds LD, Kelly S, Brown T, Campbell KJ. Interventions for preventing obesity in children. Cochrane Database Syst Rev. 2005; (3):CD001871.

6. Coon KA, Goldberg J, Rogers BL, Tucker KL. Relationships between the use of television during meals and children’s food consumption patterns. Pediatrics 2001;107(1):e7.

7. Dietz WH. Health consequences of obesity in youth: childhood predictors of adult disease. Pediatrics 1998;101(3):518-525.

8. DuRant RH, Baranowski T, Johnson M, Thompson WO. The relationship among television watching, physical activity, and body composition of young children. Pediatrics 1994;94(4):449455.

9. Epstein LH, Smith JA, Vara LS, Rodefer JS. Behavioral economic analysis of activity choice in obese children. Health Psychol. 1991:10(5);311-316.

10. Enns CW, Mickle SJ, Goldman JD. Trends in food and nutrient intakes by children in the United States. Fam Econ Nutr Rev, 2002;14(2);56-68. 
11. Committee on Progress in Preventing Childhood Obesity. Schools. Schools. In: Koplan JP, Liverman CT, Kraak VI, Wosja SL, eds. Progress in Preventing Childhood Obesity: How Do We Measure Up? Washington, DC: National Academies Press; 2007:280-325.

12. Pate RR, Ross JG: The national children and youth fitness study II: Factors associated with health-related fitness. Journal of Physical Education, Recreation and Dance. 1987:58;93-95.

13. Tucker LA: The Relationship of television viewing to physical fitness and obesity. Adolescence. 1986:21(84);797-806.

14. Troiano RP, Briefel RR, Carroll MD, Bialostosky K. Energy and fat intake of children and adolescents in the United States. Data from the National Health and Nutrition Examination Survey. Am. J. Clin. Nutri. 2000;72(5 Suppl):1343S-1353S.

15. Pate RR, Davis MG, Robinson TN, Stone EJ, McKenzie TL, Young JC. Promoting physical activity in children and youth: a leadership role for schools: a scientific statement from the American Heart Association Council on Nutrition, Physical Activity, and Metabolism (Physical Activity Committee) in collaboration with the Councils on Cardiovascular Disease in the Young and Cardiovascular Nursing. Circulation. Sep 12 2006;114(11):1214-1224.

16. McKenzie TL, Sallis JF, Prochaska JJ, Conway TL, Marshall SJ, Rosengard P. Evaluation of a Two-Year Middle-School Physical Education Intervention: M-SPAN. Med. Sci. Sports Exerc 2004: 36(8);1382-1388.

17. Gortmaker SL, Peterson K, Wiecha J, Sobol AM, Dixit S, Fox MK, Laird N. Reducing obesity via a school-based interdisciplinary intervention among youth: Planet Health. Arch Pediatr Adolesc Med. 1999;153(4):409-418.

18. Wiecha JL, Ayadi EL, Fuemmeler BF, Carter JE, Handler S, Johnson S, Strunk N, KorzecRamirez G, Gortmaker SL. Diffusion of an integrated health education program in an urban school system: Planet Health. J. Pediatric Psychol. 2004;29(6):467-474. 
19. Coleman J, Tiller CL, Sanchez J, Heath EM, Sy O, Milliken G, Dzewaltowski DA. Prevention of the epidemic increase in child risk of overweight in low-income schools: the El Paso coordinated approach to child health. Arch Pediatr Adolesc Med. 2005;159(3):217-224.

20. Dzewaltowski DA. Community Out-of-School Physical Activity Promotion. In: Smith AL, Biddle SJH, eds. Youth Physical Activity and Inactivity: Challenges and Solutions. Champaign, IL: Human Kinetics Publishers, Inc. (in Press).

21. Kelder S, Hoelscher DM, Barroso CS, Walker JL, Cribb P, Hu S. The CATCH Kids Club: a pilot after-school study for improving elementary students’ nutrition and physical activity. Public Health Nutr. 2005;8(2):133-140.

22. Martinez Vizcaino V, Salcedo Agular F, Franquelo Gutierrez R, Solera Martinez M, Sanchez Lopez M, Serrano Martinez S, Lopez Garcia E, Rodriguez Artalejo F. Assessment of an afterschool physical activity program to prevent obesity among 9- to 10-year-old children: a cluster randomized trial. Int.J.Obes. 2007:1-11.

23. Pate RR, Saunders RP, Ward DS, Felton G, Trost SG, Dowda M. Evaluation of a communitybased intervention to promote physical activity in youth: lessons from Active Winners. Am J Health Promot. 2003;17(3):171-182.

24. Robinson TN, Killen JD, Kraemer HC, Wilson DM, Matheson DM, Haskel WL, Pruitt LA, Powell TM, Owens AS, Thompson NS, Flint-Moore NM, Davis, GJ, Emig KA, Brown RT, Rochon J, Green S, Varady A. Dance and reducing television viewing to prevent weight gain in African-American girls: the Stanford GEMS pilot Study. Ethn Dis. 2003; 13(1 Suppl 1):S65S77.

25. Story M, Sherwood NE, Himes JH, Davis M, Jacobs, Jr. DR, Cartwright Y, Smyth M, Rochon J. An after-school obesity prevention program for African-American girls: the Minnesota GEMS pilot study. Ethn.Dis. 2003;13(1 Suppl 1):S54-S64. 
26. Wilson DK, Evans AE, Williams J, Mixon G, Sirard JR, Pate R. A preliminary test of a studentcentered intervention on increasing physical activity in underserved adolescents. Ann Behav Med. 2005;30(2):119-124.

27. Yin Z, Gutin B, Johnson MH, Hanes, Jr. J, Moore JB, Cavnar M, Thronburg J, Moore D, Barbeau P. An environmental approach to obesity prevention in children: Medical College of Georgia FitKid Project year 1 results. Obes Res. 2005;13(12):2153-2161.

28. Yin Z, Hanes, Jr. J, Moore JB, Humbles P, Barbeau P, Gutin B. An after-school physical activity program for obesity prevention in children: the Medical College of Georgia FitKid Project. Eval Health Prof. 2005;28(1):67-89.

29. Mahoney JL, Larson RW, Eccles JS, Lord H. Organized activities as Development Contexts for Children and Adolescents. In: Mahoney JL, Larson RW, Eccles JS. Organized Activities as Contexts of Development: Extracurricular Activities, After-School and Community Programs. Mahwah, NJ: Lawrence Erlbaum Associates; 2005:3-22.

30. McKenzie TL, Marshall SJ, Sallis JF, Conway TL. Leisure-time physical activity in school environments: An observational study using SOPLAY. Preventive Medicine, 2000;30(1):70-77.

31. McKenzie TL. The use of direct observation to assess physical activity. In: Welk GJ, ed. Physical activity assessments for health-related research. Champaign, IL: Human Kinetics; 2002:179-195.

32. McKenzie TL, Sallis JF, Nader PR. SOFIT: system for observing fitness instruction time. J. Teach. Physical Ed. 1991;11:195-205.

33. Pope RP, Coleman KJ, Gonzalez FB, Heath EM. Validity of a Revised System for Observing Fitness Instruction Time (SOFIT). Pediatr Exerc Sci. 2002;14:1-12.

34. Rowe PJ, Schuldheisz JM, van der Mars H. Validation of SOFIT for measuring physical activity of First - to Eighth-Grade Students. Pediatr. Exerc. Sci. 1997;9(2):136-149.

35. McKenzie TL, Marshall SJ, Sallis JF, Conway TL. Student activity levels, lesson context, and teacher behavior during middle school education. Res Q Exerc Sport. 2000;71(3):249-259. 
36. McKenzie TL, Catellier DJ, Conway T, Lytle LA, Grieser M, Webber LA, Pratt CA, Elder JP. Girls’ activity levels and lesson contexts in middle school PE: TAAG baseline. Med Sci Sports Exerc. 2006;38(7):1229-1235.

37. Trost SG, Dzewaltowski DA. Objectively Measured Physical Activity In School Children Attending After-School Programs. Med Sci Sports Exerc. 2007;39(5):S17.

38. McKenzie TL, Feldman H, Woods SE, Romero KA, Dahlstrom V, Stone EJ, Strikmiller PK, Williston JM, Harsha, DW. Children’s activity levels and lesson context during third-grade physical education. Res Q Exerc Sport, 1995;66(3)184-193. 
Table 1. Observations of sessions $(n=6)$ offered during seven after-school programs in Lawrence, KS.

\begin{tabular}{lcccc}
\hline \multicolumn{1}{c}{$\begin{array}{c}\text { Session } \\
\text { Type }\end{array}$} & $\begin{array}{c}\text { Session } \\
\text { Frequency* }\end{array}$ & $\begin{array}{c}\text { Session } \\
\text { Frequency } \\
\text { Per Day** }\end{array}$ & $\begin{array}{c}\text { Mean } \\
\text { Session Min } \\
\text { Per Day } \\
( \pm \text { SE) } \dagger\end{array}$ & $\begin{array}{c}\text { Mean } \\
\text { Session } \\
\text { Length in Min } \\
( \pm \text { SE) } \pm\end{array}$ \\
\hline $\begin{array}{l}\text { All Sessions } \\
\text { Snack }\end{array}$ & 168 & 4.00 & $112.1 \pm 44.2$ & $28.0 \pm 16.8$ \\
Active Recreation & 42 & 1.00 & $15.1 \pm 5.5$ & $15.1 \pm 6.8$ \\
Non Active Recreation & 64 & 1.50 & $46.8 \pm 14.9$ & $30.7 \pm 19.6$ \\
Academics & 20 & 0.48 & $13.0 \pm 9.4$ & $27.3 \pm 11.5$ \\
Enrichment & 32 & 0.76 & $27.6 \pm 10.6$ & $36.3 \pm 11.3$ \\
& 10 & 0.23 & $9.6 \pm 4.1$ & $40.5 \pm 18.7$ \\
\end{tabular}

*The total number of times these activities were observed; **The average number of times these activities were observed per day of observation; †The average total number of minutes for each of these activities in each day of observation = session frequency per day*mean session length; The average duration in minutes of each activity session when it was observed. 
Table 2. Active recreation session time spent in different intensities of physical activity for organized activities and free play. Moderate and vigorous physical activity (MVPA) is the sum of moderate and vigorous time. Data are presented as percent with number of observations in parentheses.

\begin{tabular}{ccc}
\hline Activity Intensity & Organized & Free Play \\
\hline Lying & $1 \%(25)$ & $0.1 \%(3)$ \\
Sitting & $13 \%(274)$ & $5 \%(112)$ \\
Standing & $35 \%(739)$ & $26 \%(576)$ \\
Moderate & $34 \%(733)$ & $43 \%(953)$ \\
Vigorous & $17 \%(359)$ & $25.5 \%(563)$ \\
MVPA & $51 \%(1,092)$ & $69 \%(1,516)$ \\
Total & $100 \%(2,130)$ & $100 \%(2,207)$ \\
\hline
\end{tabular}


Table 3. Time spent in different activity intensities for organized activities and free play. Data are also shown for each of the SOFIT codes for type of instruction during the activity session. Data are presented as percent with number of observations in parentheses.

\begin{tabular}{ccccccc}
\hline $\begin{array}{l}\text { Activity Intensity/ } \\
\text { Session Type }\end{array}$ & Management & Knowledge & Fitness & Game-Play & Skill & Free-Play \\
\hline Lying & $1 \%(2)$ & $0 \%(0)$ & $1 \%(1)$ & $1 \%(14)$ & $2 \%(7)$ & $0.5 \%(1)$ \\
Organized & $0 \%(0)$ & $0 \%(0)$ & $0 \%(0)$ & $0 \%(0)$ & $0 \%(0)$ & $0.2 \%(3)$ \\
Free Play & & & & & & \\
Sitting & $26.5 \%(82)$ & $46 \%(40)$ & $4 \%(5)$ & $10 \%(101)$ & $5.5 \%(20)$ & $12 \%(26)$ \\
Organized & $4.5 \%(7)$ & $0 \%(0)$ & $0 \%(0)$ & $6 \%(7)$ & $0 \%(0)$ & $5 \%(98)$ \\
Free Play & & & & & \\
Standing & $47 \%(144)$ & $38 \%(33)$ & $25 \%(33)$ & $30 \%(304)$ & $50 \%(180)$ & $21 \%(45)$ \\
Organized & $41 \%(65)$ & $50 \%(1)$ & $0 \%(0)$ & $32 \%(40)$ & $0 \%(0)$ & $24.5 \%(470)$ \\
$\quad$ Free Play & & & & &
\end{tabular}


Free Play $\quad 45 \%(70) \quad 50 \%(1) \quad 40 \%(2) \quad 38 \%(48) \quad 0 \%(0) \quad 43 \%(832)$

Vigorous

$\begin{array}{lcccccc}\text { Organized } & 3 \%(8) & 2 \%(2) & 25 \%(33) & 21 \%(211) & 14 \%(52) & 25 \%(53) \\ \text { Free Play } & 10 \%(15) & 0.0 \%(0) & 60 \%(3) & 24 \%(30) & 0 \%(0) & 27 \%(515)\end{array}$

MVPA

$\begin{array}{lcccccc}\text { Organized } & 26 \%(81) & 16 \%(14) & 70.5 \%(93) & 59 \%(606) & 43 \%(156) & 66 \%(142) \\ \text { Free Play } & 54 \%(85) & 50 \%(1) & 100 \%(5) & 62 \%(78) & 0 \%(0) & 70 \%(1,347)\end{array}$

Total

\begin{tabular}{ccccccc} 
Organized & $14.5 \%(309)$ & $4 \%(87)$ & $6 \%(132)$ & $48.1 \%$ & $17 \%(363)$ & $10 \%(214)$ \\
Free Play & $7 \%(157)$ & $0.1 \%(2)$ & $0.2 \%(5)$ & $6 \%(125)$ & $0 \%(0)$ & $87 \%(1,918)$ \\
\hline
\end{tabular}


Table 4. Time that activity leaders spent promoting or discouraging physical activity, presented by different activity intensities and whether the sessions observed were organized activities or free play. Data are presented as percent with number of observations in parentheses.

\begin{tabular}{|c|c|c|c|c|}
\hline \multirow{2}{*}{$\begin{array}{l}\text { Activity Intensity/ } \\
\text { Session Type }\end{array}$} & \multicolumn{2}{|c|}{ Physical Activity During Session* } & \multicolumn{2}{|c|}{ Physical Activity Outside of Session** } \\
\hline & Promote & Discourage & Promote & Discourage \\
\hline \multicolumn{5}{|l|}{ Lying } \\
\hline Organized & $3 \%(7)$ & $0 \%(0)$ & $0 \%(0)$ & $0 \%(0)$ \\
\hline Free Play & $0 \%(0)$ & $0 \%(0)$ & $0 \%(0)$ & $0 \%(0)$ \\
\hline \multicolumn{5}{|l|}{ Sitting } \\
\hline Organized & $10 \%(27)$ & $25 \%(6)$ & $0 \%(0)$ & $0 \%(0)$ \\
\hline Free Play & $0 \%(0)$ & $19 \%(3)$ & $0 \%(0)$ & $0 \%(0)$ \\
\hline \multicolumn{5}{|l|}{ Standing } \\
\hline Organized & $32 \%(88)$ & $46 \%(11)$ & $0 \%(0)$ & $0 \%(0)$ \\
\hline Free Play & $36 \%(4)$ & $75 \%(12)$ & $0 \%(0)$ & $0 \%(0)$ \\
\hline \multicolumn{5}{|l|}{ Moderate } \\
\hline Organized & $41 \%(112)$ & $21 \%(5)$ & $0 \%(0)$ & $0 \%(0)$ \\
\hline Free Play & $46 \%(5)$ & $0 \%(0)$ & $0 \%(0)$ & $0 \%(0)$ \\
\hline \multicolumn{5}{|l|}{ Vigorous } \\
\hline Organized & $14 \%(39)$ & $8 \%(2)$ & $0 \%(0)$ & $0 \%(0)$ \\
\hline
\end{tabular}



Free Play
$18 \%$ (2)
$6 \%(1)$
0\% (0)
0\% (0)

\section{MVPA}

Organized

55\% (151)

$29 \%$ (7)

$0 \%(0)$

0\% (0)

Free Play

$64 \%(7)$

6\% (1)

0\% (0)

$0 \%(0)$

Total

Organized

92\% (273)

$8 \%$ (24)

0\% (0)

$0 \%(0)$

Free Play

41\% (11)

$59 \%$ (16)

$0 \%(0)$

$0 \%(0)$

Total number of observations for these data was 297; *During refers to verbal or nonverbal leader behaviors promoting or

discouraging child physical activity during the after-school lesson; ** Outside refers to verbal or nonverbal leader behaviors promoting or discouraging child behavior outside of the after-school setting. 
Table 5. Percent of time (number of observations) of leader behavior promoting or discouraging physical activity by session context.

\begin{tabular}{|c|c|c|c|c|}
\hline \multirow{2}{*}{$\begin{array}{l}\text { Activity Intensity/ } \\
\text { Session Type }\end{array}$} & \multicolumn{2}{|c|}{ Physical Activity During Session* } & \multicolumn{2}{|c|}{ Physical Activity Outside of Session** } \\
\hline & Promote & Discourage & Promote & Discourage \\
\hline \multicolumn{5}{|l|}{ Management } \\
\hline Organized & $5 \%(13)$ & $25 \%(6)$ & $0 \%(0)$ & $0 \%(0)$ \\
\hline Free Play & $0 \%(0)$ & $94 \%(15)$ & $0 \%(0)$ & $0 \%(0)$ \\
\hline \multicolumn{5}{|l|}{ Knowledge } \\
\hline Organized & $1 \%(2)$ & $67 \%(16)$ & $0 \%(0)$ & $0 \%(0)$ \\
\hline Free Play & $0 \%(0)$ & $0 \%(0)$ & $0 \%(0)$ & $0 \%(0)$ \\
\hline \multicolumn{5}{|l|}{ Fitness } \\
\hline Organized & $20 \%(54)$ & $8 \%(2)$ & $0 \%(0)$ & $0 \%(0)$ \\
\hline Free Play & $0 \%(0)$ & $0 \%(0)$ & $0 \%(0)$ & $0 \%(0)$ \\
\hline \multicolumn{5}{|l|}{ Game Play } \\
\hline Organized & $46 \%(125)$ & $0 \%(0)$ & $0 \%(0)$ & $0 \%(0)$ \\
\hline Free Play & $0 \%(0)$ & $0 \%(0)$ & $0 \%(0)$ & $0 \%(0)$ \\
\hline \multicolumn{5}{|l|}{ Skill } \\
\hline Organized & $28 \%(76)$ & $0 \%(0)$ & $0 \%(0)$ & $0 \%(0)$ \\
\hline Free Play & $0 \%(0)$ & $0 \%(0)$ & $0 \%(0)$ & $0 \%(0)$ \\
\hline
\end{tabular}

Free Play 

Organized
$1 \%(3)$
0\% (0)
$0 \%(0)$
0\% (0)
Free Play
$100 \%(11)$
$6 \%(1)$
0\% (0)
$0 \%(0)$

Total
Organized
92\% (273)
8\% (24)
0\% (0)
0\% (0)
Free Play
41\% (11)
$59 \%(16)$
$0 \%(0)$
$0 \%(0)$

Total number of observations for these data was 297.

*During refers to verbal or nonverbal leader behaviors promoting or discouraging child physical activity during the after-school lesson.

**Outside refers to verbal or nonverbal leader behaviors promoting or discouraging child behavior outside of the after-school setting. 